\title{
Teoria das Representações Sociais como ferramenta metodológica nos processos de Design
}

\author{
Social Representation Theory as a methodological \\ tool in the Design processes
}

teoria das

representações sociais, metodologia,

design
Este artigo apresenta as possibilidades de aplicação a Teoria das Representações Sociais no campo do Design da Informação, particularmente no desenvolvimento de artefatos cujas interfaces estejam de alguma forma vinculadas às vivências dos indivíduos nos grupos sociais nos quais estejam inseridos. Descreve os resultados obtidos com a confecção de um jogo de tabuleiro ambientado e configurado para ensinar e valorizar o sentimento de pertencimento a um bairro histórico e socialmente relevante da Zona do Sul do Recife, capital do estado de Pernambuco, e aponta a possibilidade de que o uso de um artefato feito sob medida para uma realidade local consiga acessar o campo das representações já compartilhadas entre os grupos de moradores, havendo indícios também de contribuição nos processos de ensino e aprendizagem de conteúdos, tanto os que foram oferecidos pela ferramenta quanto os já trabalhados em sala de aula ou no convívio familiar.

This paper presents the practical application possibilities of the Social Representations Theory in the field of Information Design, particularly in the development of artifacts which interfaces are somehow linked to the experiences of individuals in social groups. Describes the results obtained with a board game set to teach and enhance the feeling of belonging to a historical and socially relevant neighborhood of the South Area of Recife, the capital of the Pernambuco state, and points to the possibility that the use of a device specially configured for a local reality can access the field of representations already shared among groups of residents. There is also evidence of contribution in the teaching and learning processing of the contents offered by the tool and also the ones already worked in the classroom or in the family context.

\section{Introdução}

A Teoria das Representações Sociais (TSR) foi fundada pelo romeno naturalizado francês Serge Moscovici (1921 - ) no contexto do desenvolvimento da psicologia social europeia, em meados dos anos 1960. Com a publicação, em 1961, do livro "La Psychanalyse son Image 
et son Public", traduzido em parte no Brasil como Representação Social da Psicanálise, ele manifesta o seu extremo interesse em investigar como se produz e como se transforma o conhecimento, especialmente o conhecimento do senso comum. Moscovici (1961) queria entender como o senso comum se apropria dos conhecimentos produzidos nas mais diversas áreas, conferindo-lhes sentido através da criação do que chamou de representações sociais.

O termo representação social é derivado do conceito de "representação coletiva” do sociólogo francês Émile Durkheim (18581917), fundador da escola francesa de sociologia, e responsável pelo início de uma investigação mais profunda da vida social centrada não apenas no indivíduo e naquilo que está presente em todas as consciências particulares (vestir-se, comer, locomover-se etc), mas no conjunto de forças que regem os grupos. Para ele, a vida social é essencialmente simbólica e se expressa através de fatos sociais que traduzem maneiras de pensar, de agir e de sentir que são exteriores aos indivíduos.

Na tentativa de estabelecer a sociologia como ciência autônoma, Durkheim defendia uma separação radical entre representações individuais e representações coletivas. Para o sociólogo, caberia à psicologia o estudo das primeiras, enquanto a sociologia ficaria encarregada de estudar as últimas. A rígida divisão proposta por Durkheim abriu caminhos ao estudo dos processos de significação ocorridos entre os grupos sociais, mas conferiu aos fenômenos configurações estanques e isoladas, impossibilitando exames mais aprofundados sobre as representações coletivas e seus impactos sobre as consciências individuais.

Serge Moscovici propõe uma atualização das ideias de Durkheim ao chamar a atenção para as especificidades dos fenômenos representativos nas sociedades contemporâneas, caracterizados por intensidade e fluidez das trocas e comunicações, desenvolvimento da ciência, pluralidade e mobilidade social (MOSCOVICI, 1981). Para ele, as representações sociais seriam uma forma de conhecimento socialmente partilhado e elaborado. São sistemas que registram nossa relação com o mundo e com os outros, orientando e organizando as condutas e as comunicações sociais. Ao mesmo tempo, elas interferem nos processos, diversificando a difusão e a assimilação dos conhecimentos, os desenvolvimentos individual e coletivo, a definição das identidades pessoais e sociais, a expressão dos grupos e as transformações sociais (JODELET, 1991).

A Teoria das Representações Sociais propõe uma investigação mais aprofundada do conteúdo que constitui esta espécie de fundo cultural acumulado nas sociedades ao longo de sua história e que circula nos grupos sob a forma de crenças amplamente compartilhadas, de valores considerados como básicos e de referências históricas e culturais que conformam a memória coletiva e até a identidade da própria sociedade. Desta forma, pode tornar-se ferramenta teórica e metodológica para projetos de Design, particularmente no caso de 
artefatos que dependam do acesso a este fundo cultural para serem compreendidos, assimilados ou utilizados, como é o caso de um jogo de tabuleiro desenvolvido como parte projetual de uma pesquisa de Mestrado, defendida na Universidade Federal de Pernambuco (UFPE) em 2012, e cuja metodologia e resultados serão apresentados a seguir.

\section{O bairro e o jogo}

Localizado na Zona Sul do Recife, o bairro de Brasília Teimosa tem uma história relevante no contexto da formação social da capital pernambucana. Surgiu em 1947 como a primeira ocupação urbana da cidade, realizada por um grupo de pescadores que invadiu uma área de 64,5 hectares à beira-mar da praia do Pina aterrada em 1909 para servir como parque de tancagem para o Porto do Recife, mas que permaneceu desocupada porque o terreno estava em litígio.

As primeiras famílias de pescadores fundaram a Colônia Z-1, até hoje atuante no bairro que recebeu o nome de "Brasília Teimosa" em homenagem à capital brasileira, em construção na mesma época do início da ocupação. O adjetivo "Teimosa” foi acrescentado por sintetizar a luta dos moradores pela posse do terreno e a resistência às inúmeras tentativas de desocupação da área que, pela localização privilegiada, virou alvo da especulação imobiliária e de interesses políticos e econômicos de diversos grupos.

Até os anos 80, o bairro cresceu desordenadamente e a maioria dos habitantes vivia em palafitas, casebres de madeira fincados sobre a maré e sujeitos a todas as intempéries do terreno irregular. As palafitas predominaram na paisagem até pelo menos 1982, quando a área foi incluída no programa Promoradia, financiado pelo antigo Banco Nacional da Habitação, e seus ocupantes encaminhados para o conjunto habitacional Vila da Prata, também no bairro. Novas ocupações foram realizadas e mais duas intervenções feitas, em 1986 e 1989 , sem que as promessas de urbanização tenham sido cumpridas.

Apenas em 2004, depois de projetos capitaneados pelos governos Federal, Estadual e Municipal, as últimas palafitas foram derrubadas e seus moradores realocados para habitacionais construídos no bairro e em outras localidades do Recife. Onde antes se viam barracos suspensos e ruelas com esgoto a céu aberto, agora estão casas de alvenaria, ruas pavimentadas e uma orla com 1,3 km de extensão chamada de Avenida Brasília Formosa. O bairro virou Zona Especial de Interesse Social (ZEIS) e o passado comum e as histórias de luta permanecem vivos nos discursos dos moradores de Brasília Teimosa, onde parece haver um sentimento comum, uma sensação de "pertencimento" que para o sociólogo Zygmunt Bauman é uma das peças fundamentais para compor o "quebra-cabeças" da construção das identidades individual e coletiva (Bauman, 2005: 17).

A história do bairro inspirou a criação do jogo Passeio por Brasília Teimosa, cujo objetivo é ser usado como ferramenta em sala de aula 
para contar a história do local de maneira interativa e trabalhar a importância da preservação do espaço, através dos conteúdos de educação ambiental e cidadania. O público alvo são crianças com idades entre 11 e 14 anos e o levantamento das informações foi realizado em bases de dados governamentais, reportagens e visitas, além de registros em foto e vídeo de pontos que deveriam servir como referências. O tabuleiro (Figura 1) foi criado a partir do mapa do bairro, sendo observada rapidamente a necessidade de uma síntese das principais ruas em virtude da grande quantidade de pequenas ruelas. Esta fase revelou a necessidade de também sintetizar a paisagem, uma vez que o bairro apresenta uma profusão de construções semelhantes

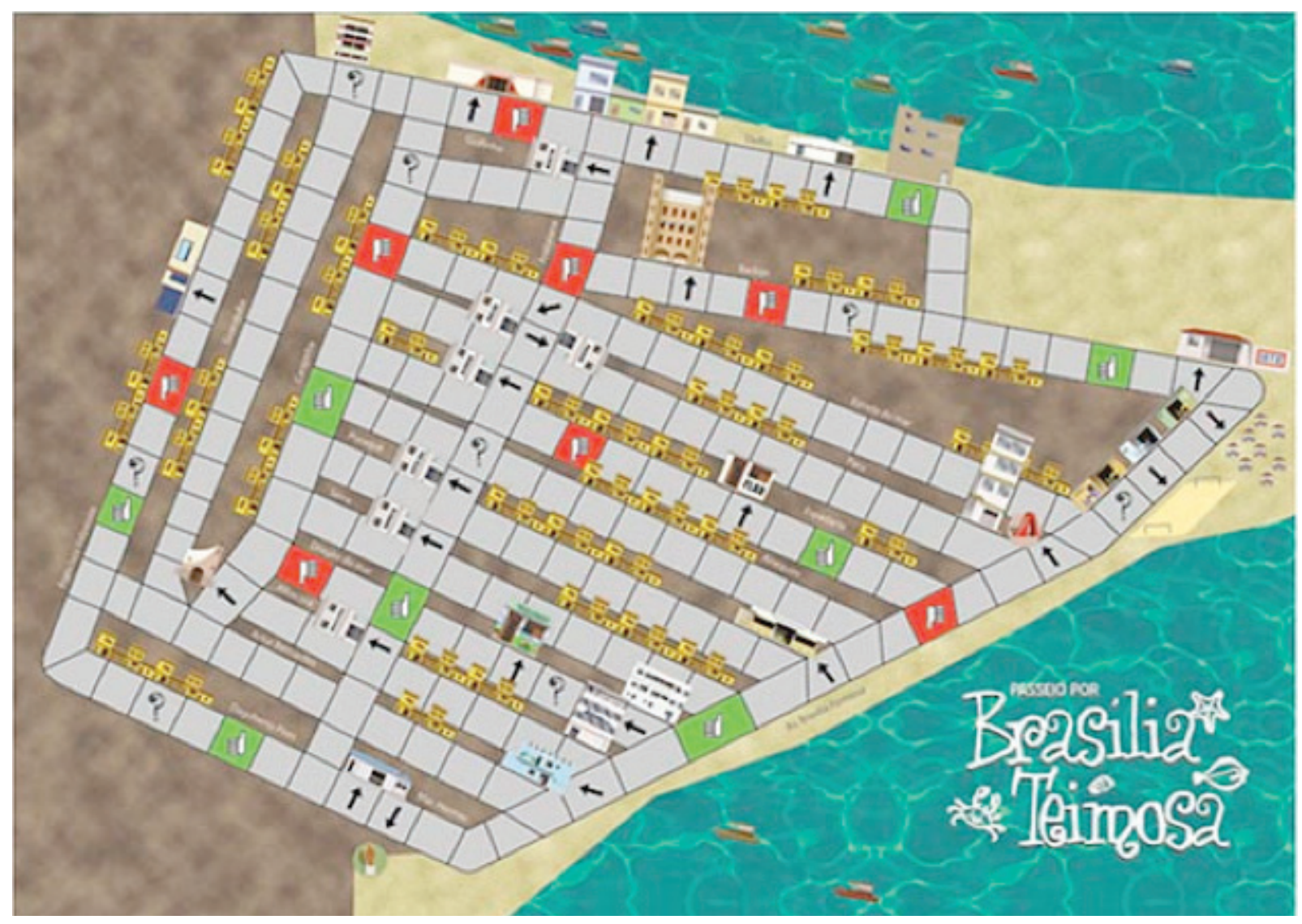

Figura 1 Tabuleiro

impossíveis de serem reproduzidas em sua totalidade. Assim, optou-se por identificar as edificações mais significativas para a mecânica do jogo e dar a elas uma modelagem em formato de ilustrações mais realistas em relação à sua arquitetura e configuração. Foram usadas vinte e oito ilustrações semelhantes à retratada na (Figura 2). 


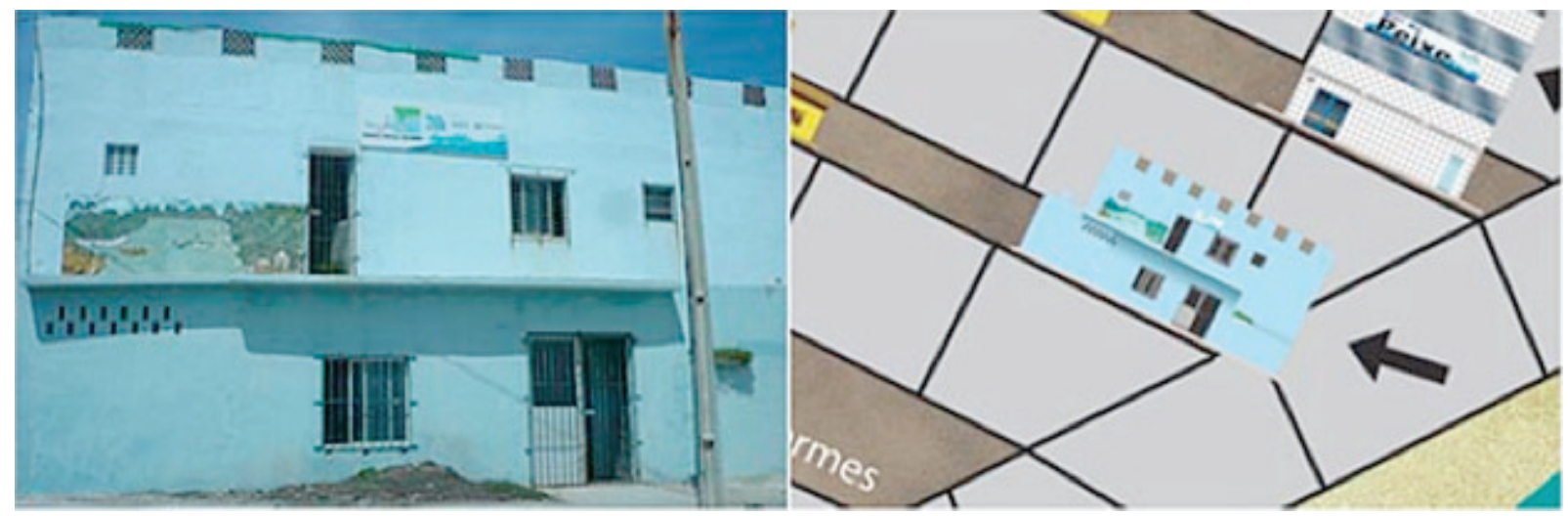

Figura 2 Exemplo de imóvel modelado para o tabuleiro

Em seguida, optou-se por sintetizar o restante das edificações a partir das linhas originais dos grupos de casas. O objetivo era representar o conjunto arquitetônico geral (Figura 3) através da inserção de ilustrações de pequenas casas de cor amarela.
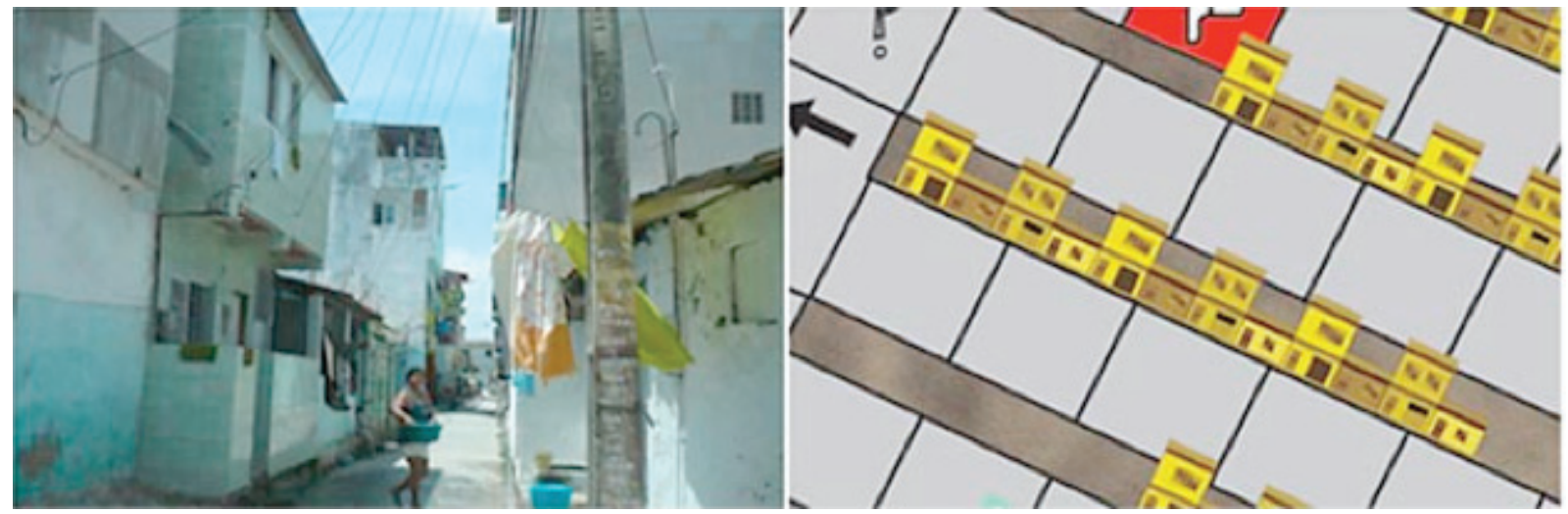

Figura 3 Exemplo de síntese para o casario geral

Ainda para a confecção do tabuleiro foi observada a nomenclatura dos logradouros. Há pelo menos uma década as principais ruas do bairro têm nomes de peixes, mas elas continuam sendo chamadas pelas letras do alfabeto, como no início da ocupação. Este fato orientou a mecânica do jogo, uma vez que ela foi estabelecida de modo que não haja um circuito fechado a ser percorrido por todos os jogadores. Antes do início da partida, cada jogador retira uma carta OBJETIVO (Figura 4) que determina locais que deve percorrer antes de voltar à escola, ponto de partida e chegada dos jogadores. O jogador é livre para escolher o percurso, entrando em contato direto com a nova nomenclatura dos logradouros. Ganha quem percorrer os locais em menos tempo, movimentando-se através de um dado. As cartas OBJETIVO são quinze (15). 


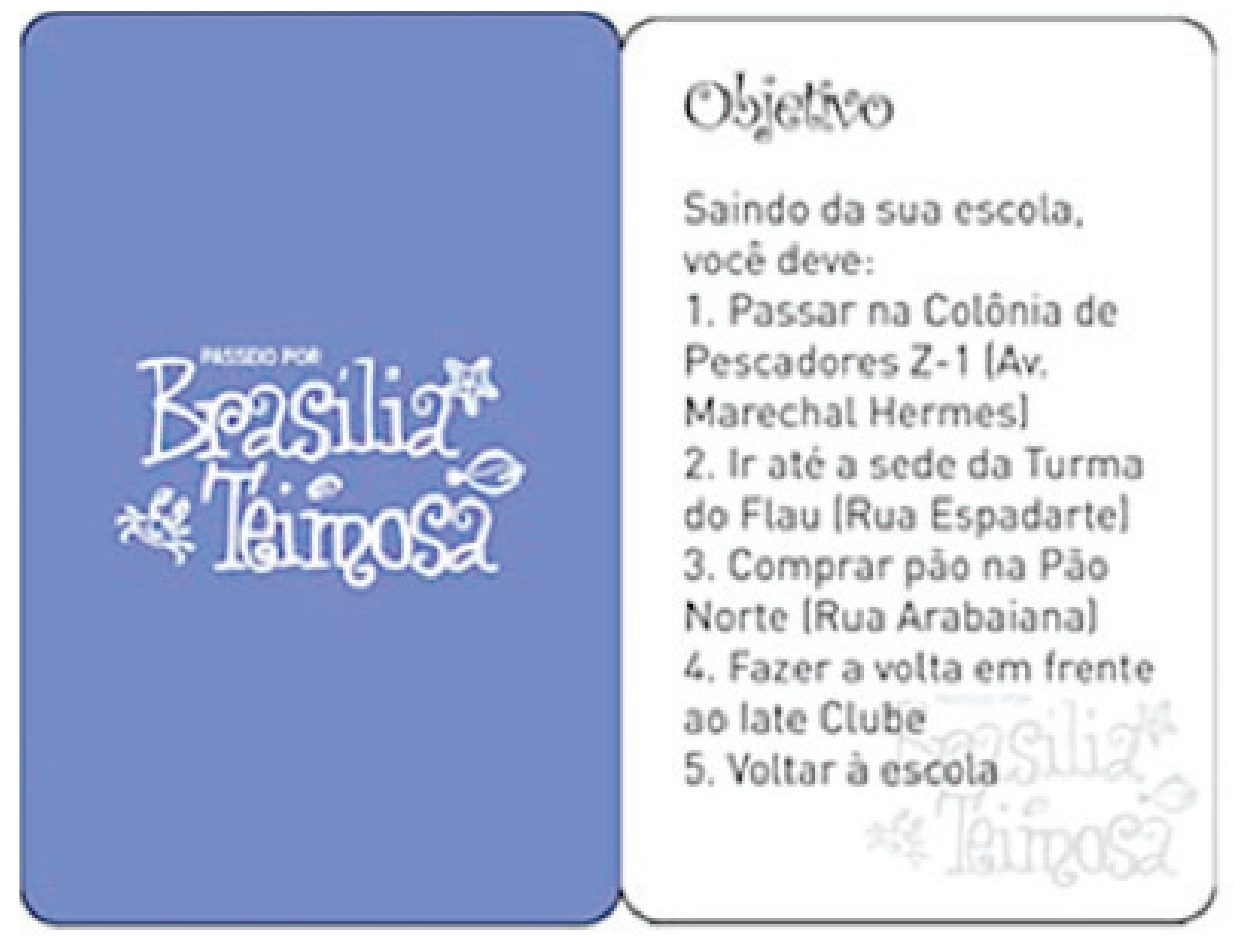

Figura 4 Cartas objetivo

A fase seguinte foi imaginar formas de tornar o percurso mais dinâmico e imprevisível, através da inclusão das cartas de AVANÇO e RETROCESSO (Figura 5), que permitem ao jogador pular casas, jogar o dado novamente, voltar casas ou ficar uma rodada sem jogar. As cartas são utilizadas quando o jogador cai em uma das casas sinalizadas no tabuleiro com as cores VERDE e VERMELHA, sendo a primeira para avanço e a segunda para retrocesso. A sinalização é reforçada pelo ícone de um polegar para cima ou para baixo (Figura 6). Ao cair em uma dessas casas, o jogador deve tirar uma carta e ler em voz alta seu conteúdo.

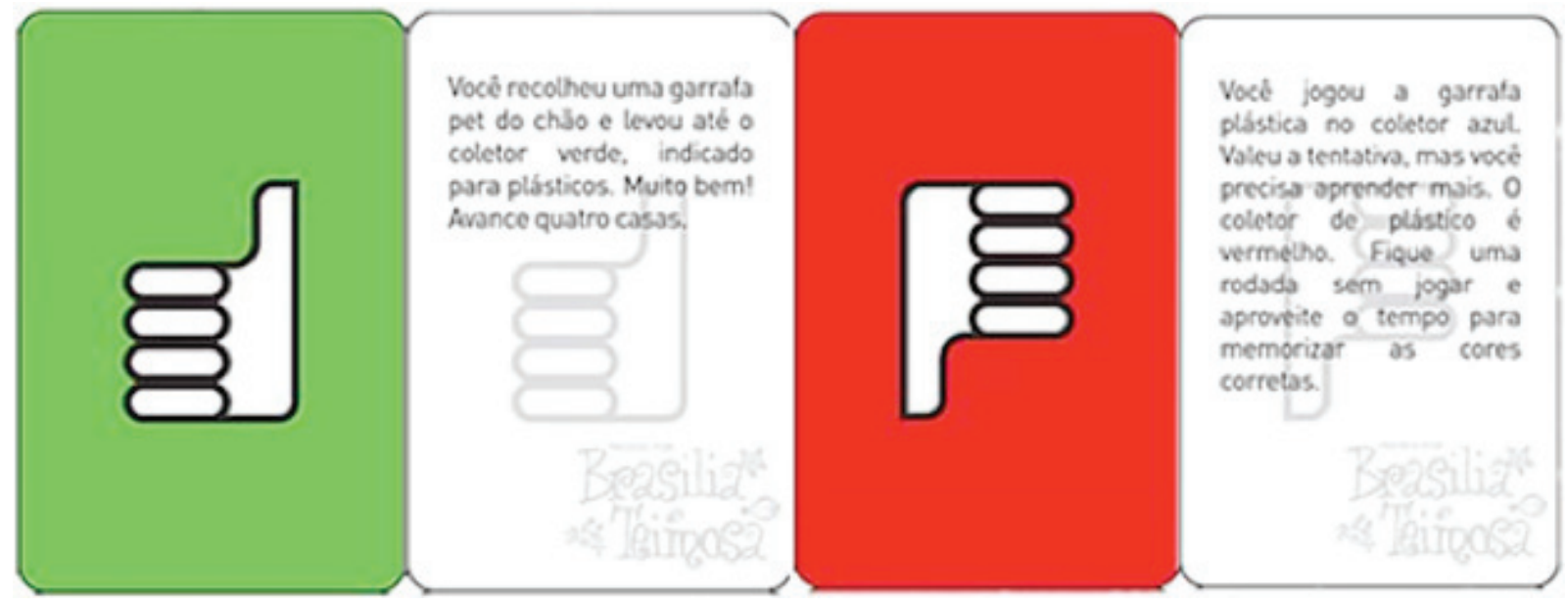

Figura 5 Cartas de avanço e retrocesso 


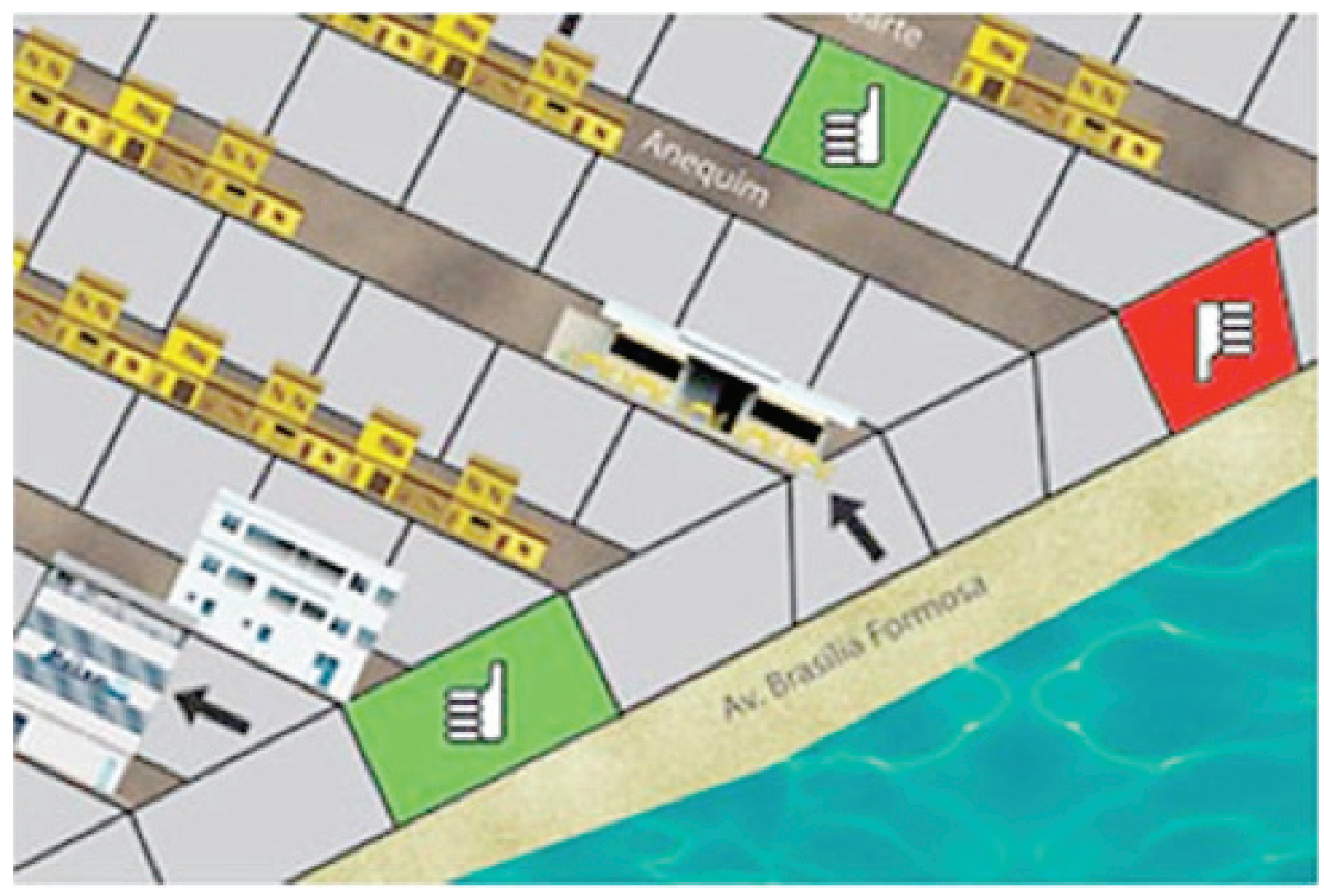

Figura 6 Casas com a sinalização de avanço e retrocesso

As cartas de AVANÇO ou RETROCESSO foram utilizadas para a inserção do conteúdo de educação ambiental e cidadania e trazem situações vividas no cotidiano dos moradores, com referências a locais e pessoas conhecidas no bairro. O jogo possui um total de 50 cartas deste tipo, sendo 25 de cada modalidade.

O passo seguinte foi incluir informações sobre os patrimônios do bairro e sobre a sua história e particularidades. $\mathrm{O}$ formato escolhido foi a introdução das cartas VOCÊ SABIA? (Figura 7). O jogador tem acesso a essas cartas ao cair em uma das casas sinalizadas por um ponto de interrogação (Figura 8). Ao chegar em uma delas, deve tirar uma carta e ler seu conteúdo em voz alta. Como estímulo, deve jogar o dado novamente e andar a quantidade de casas que tirar.

Por ser o conteúdo mais significativo, as cartas VOCÊ SABIA? - vinte e cinco (25) no total - ganharam tratamento diferenciado e trazem fotografias ocupando o verso. A frente possui textos com informações sobre o bairro, divididas em temas como história, geografia, sociedade, ações sociais e curiosidades sobre os peixes que dão nome às ruas. 

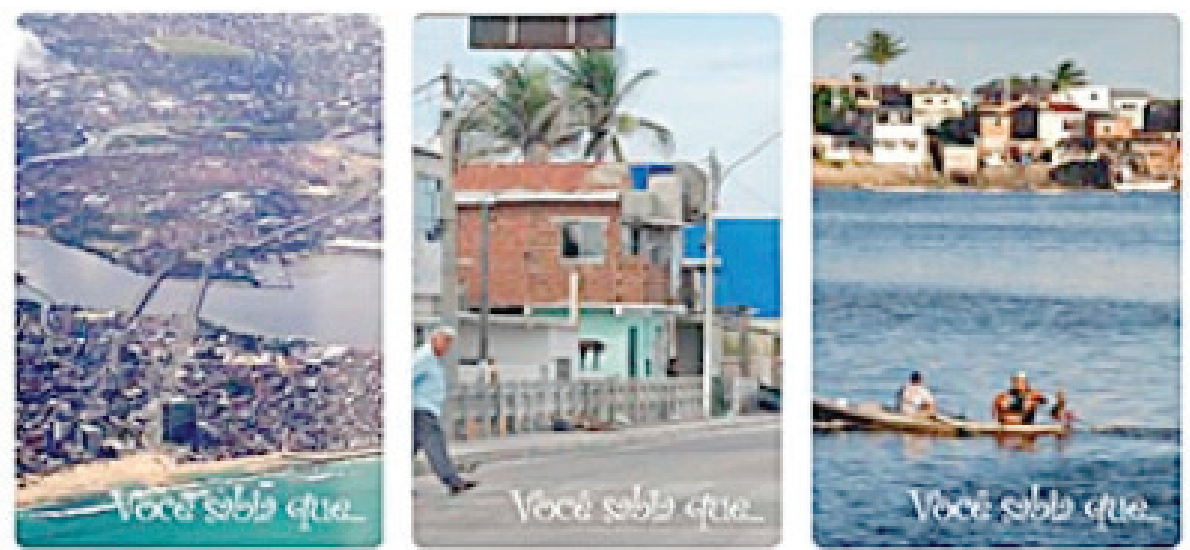

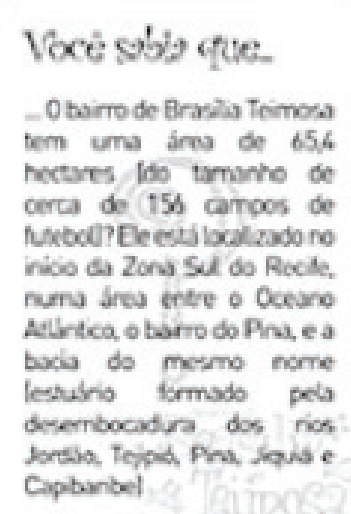

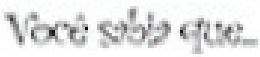

o tarro de Bracla Temora tem unu populaxblo estimada de $30 \mathrm{mi}$ perian? Segundo incivitol Braviero de Geografo e Estyistca dingio responsivel por contar a nimero de pestas eue naxiem e varm no Brad, o barro represerta $1 / 44 \%$ de toda a populacbo do Riecte.

\section{Vocé sobja que}

O Obirro de Bracia Temosa ctíloraliono em uma Zon Especis de rtcresse Social Bewl? bto signifa que o boirto e considerodo uma brea especiul do Recile, ande a grarta de cras e de boas. condicbles de vida sto coneiderodrs pricridudes, epecivimente para os mos pobres.

Figura 7 Cartas Você sabia?

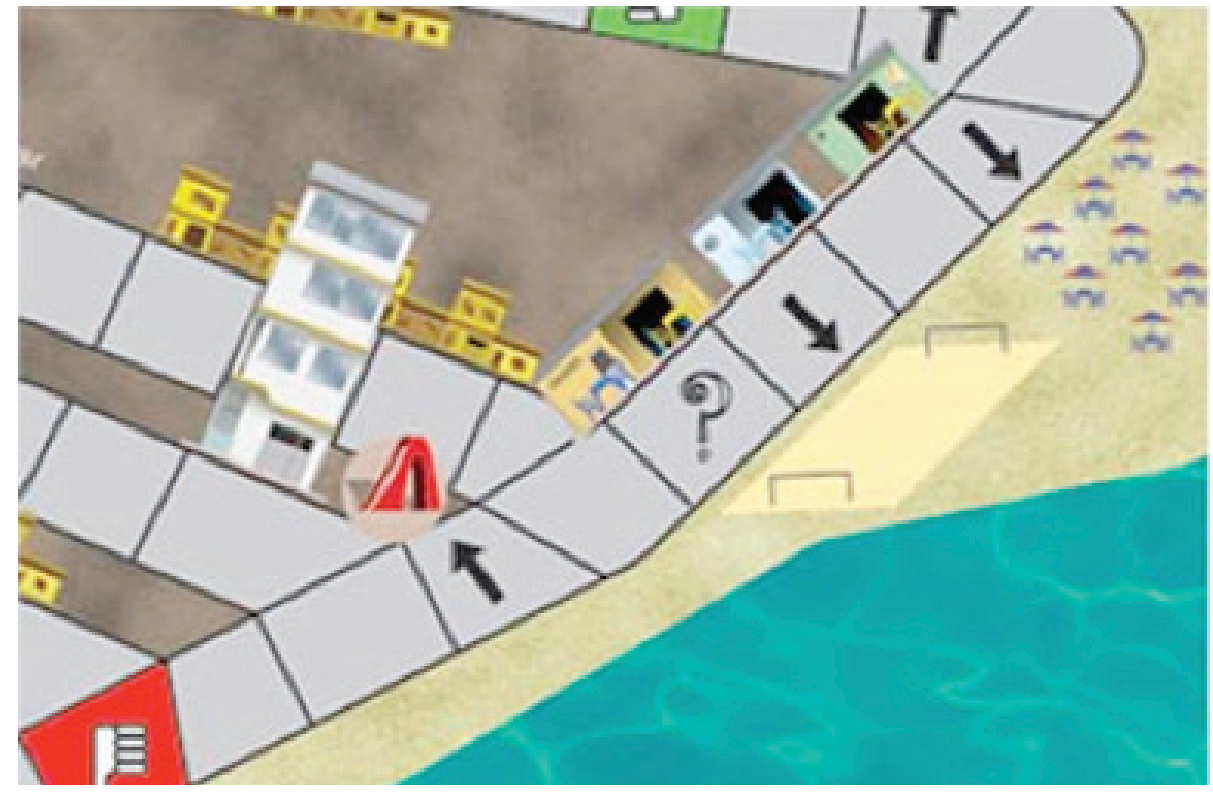

Figura 8 Detalhe de casa sinalizada com sinal de interrogação 


\section{Investigação das representações sociais}

Ao longo do processo de configuração do Design e definição da mecânica do jogo apresentou-se a necessidade de entender como estava estruturada a percepção dos sujeitos sobre o bairro onde moravam. Só assim seria possível entender se o artefato configurado sob medida para aquela realidade tinha sido capaz de provocar alguma mudança na maneira de perceber o bairro ou contribuído no processo de ensino e aprendizagem de conteúdos sobre Brasília Teimosa trabalhados nas escolas do bairro.

Assim, a pesquisa entrou em contato com os fundamentos da Teoria das Representações Sociais e particularmente com uma de suas abordagens, a Teoria do Núcleo Central, criada por Jean-Claude Abric (Abric, 1994: 78). Para ele, uma representação social é um conjunto organizado de informações, opiniões, atitudes e crenças a respeito de um dado objeto. Socialmente produzida, ela é facilmente marcada pelos valores correspondentes ao sistema sócio-ideológico e à história do grupo que a veicula.

No entanto, ainda segundo Abric, nem todos os elementos têm a mesma importância. Alguns são essenciais, outros são importantes e os demais são secundários. Para conhecer de fato uma representação social sobre determinado objeto para determinado grupo seria, então, essencial, apreender a sua organização e a hierarquia que esses elementos mantêm entre si.

Dentro da perspectiva da Teoria do Núcleo Central, é possível extrair esta organização interna das representações sociais a partir de um método de associação livre de palavras, seguida da observação de dois indicadores de hierarquia: a frequência de um item e a sua ordem de importância.

A etapa de associação livre propõe, a partir de uma palavra indutora, solicitar ao sujeito que liste 05 (cinco) palavras ou expressões que lhe vêm à mente. Após a escolha das cinco palavras, o mesmo sujeito é solicitado a classificar sua produção em função da importância que ele dá a cada termo para definir o objeto em questão. O item mais importante deve receber o número 1, o segundo mais importante, o número 2 e, assim, sucessivamente. Essa classificação permite hierarquizar as palavras, já que nem sempre a primeira palavra associada é necessariamente a mais importante para o sujeito.

É através do cruzamento entre a quantidade de evocações de uma palavra (frequência) e a sua ordem de classificação (importância) que se pode chegar ao núcleo central da representação e aos seus núcleos periféricos. Os dados são trabalhados no software EVOC - Ensemble de Programmes PermettantI' Analyse dês Évocations, que oferece um quadro semelhante a este como resultado: 


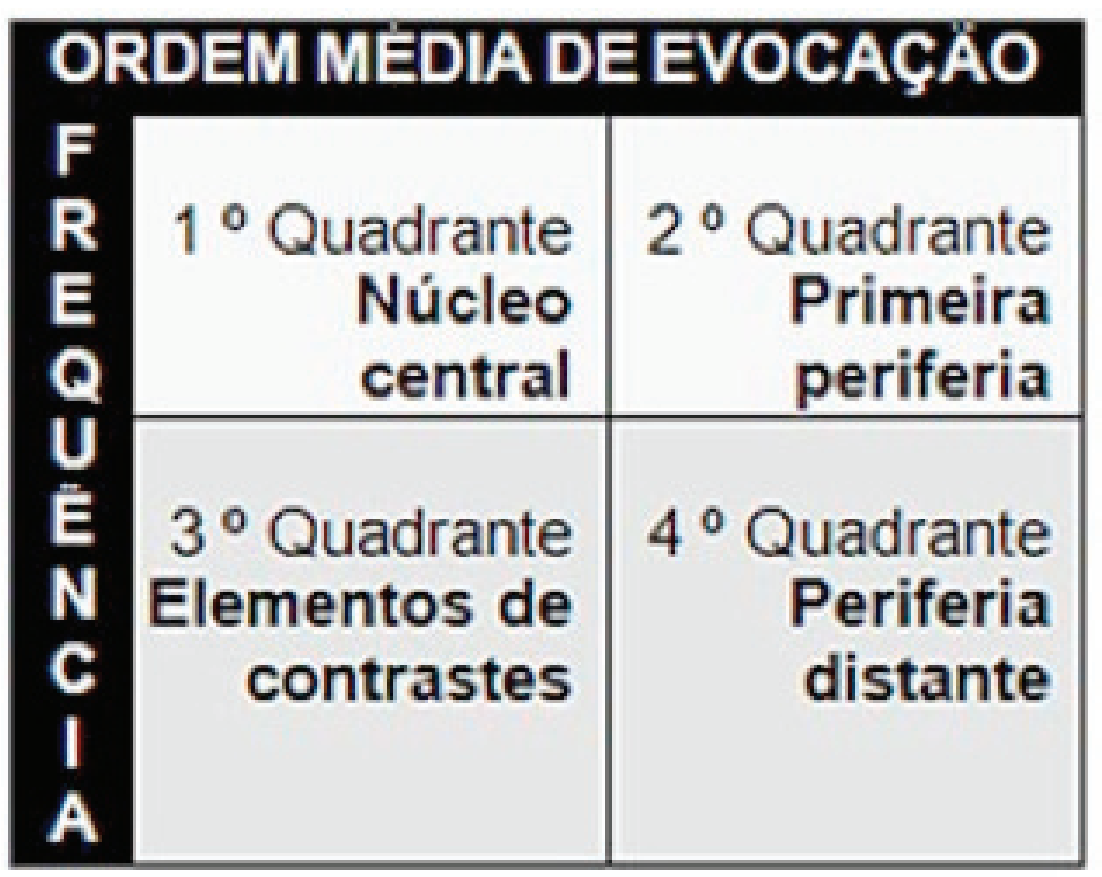

Figura 9 Resultado obtido com o software EVOC

Sendo:

1. Núcleo central: palavras ou expressões mais frequentes e consideradas mais importantes na avaliação dos participantes;

2. Primeira periferia: palavras ou expressões mais frequentes classificadas nos últimos lugares no critério dos participantes;

3. Elementos de contraste: palavras ou expressões menos frequentes classificadas como as mais importantes pelos sujeitos;

4. Periferia distante: palavras ou expressões menos frequentes e classificadas nos últimos lugares pelos sujeitos

Segundo Jean-Claude Abric, o núcleo central é diretamente ligado e determinado pelas condições históricas, sociológicas e ideológicas do grupo em questão, sendo fortemente marcado pela memória coletiva e pelo sistema de normas ao qual ele se refere. Já os quadrantes periféricos são mais sensíveis e determinados pelas características do contexto imediato, sendo os primeiros a absorverem novas informações ou eventos suscetíveis de colocar em questão o núcleo central. Um quadro elaborado pelo próprio Abric (1994) ajuda a entender as relações e as contradições entre os núcleos que compõem a representação.

A partir desta proposta metodológica, um estudo inicial foi realizado com a participação de 73 estudantes com idades 11 e 14 anos, integrantes do sétimo ano do Ensino Fundamental da Escola Estadual Assis Chateaubriand, localizada em Brasília Teimosa. Todo procedimento foi explicado verbalmente. Não foi fornecido 


\begin{tabular}{|l|l|}
\hline SISTEMA CENTRAL & SISTEMA PERIFÉRICO \\
\hline $\begin{array}{l}\text { Ligado à memória coletiva e à } \\
\text { história do grupo }\end{array}$ & $\begin{array}{l}\text { Permite a integração das experiências e histórias } \\
\text { individuais }\end{array}$ \\
\hline $\begin{array}{l}\text { Consensual; } \\
\text { define a homogeneidade do grupo }\end{array}$ & Suporta a heterogeneidade do grupo \\
\hline $\begin{array}{l}\text { Estável } \\
\text { Coerente } \\
\text { Rígido }\end{array}$ & $\begin{array}{l}\text { Flexivel } \\
\text { Suporta as contradições }\end{array}$ \\
\hline $\begin{array}{l}\text { Resistente à mudança } \\
\text { Pouco sensivel ao contexto } \\
\text { imediato }\end{array}$ & Sensivel ao contexto imediato \\
\hline $\begin{array}{l}\text { Funçöes: Gera a significação da } \\
\text { representação; determina sua } \\
\text { organização }\end{array}$ & $\begin{array}{l}\text { Funçöes: Permite adaptação à realidade } \\
\text { concreta; permite a diferenciação do conteúdo; } \\
\text { protege o sistema central }\end{array}$ \\
\hline
\end{tabular}

Figura 10 Resumo das relações entre os núcleos central e periférico da representação social

tempo para a realização do exercício, nem condição imposta para a participação. Reunidos em sala de aula, todos responderam ao questionário:

- Quando eu falo as palavras "Brasília Teimosa", quais são as cinco (05) primeiras palavras que lhe vêm à mente?

- Por favor, agora coloque ao lado das palavras uma numeração (de 1 a 5), que indique a ordem de importância de cada uma delas, para você.

- Agora, por favor, explique porque você escolheu esta palavra como a primeira mais importante.

As respostas à terceira pergunta não são incluídas no software, mas servem como informações que fundamentam a análise posterior do pesquisador. Antes da tabulação, no entanto, procurou-se agrupar a série de evocações feitas pelos sujeitos em torno de uma mesma unidade de sentido, como forma de analisá-las sob um mesmo conceito. O quadro a seguir traz as palavras agrupadas e os conceitos apresentados nos resultados finais. 


\begin{tabular}{l|l} 
CONCETO & PALAVRAS EVOCADAS \\
\hline Casas & Casa, Moradia \\
\hline Moradores & Pessoas, População \\
\hline Mercado & Mercadinho, Comércio, Feiras, Lojas \\
\hline Drogas & Maconha, Crack, Tráfico \\
\hline Violência & Ladrões, Tiroteio, Criminalidade, Assalto \\
\hline Diversão & $\begin{array}{l}\text { Jogos, Jogar bola, Brincadeiras, Shows, Suingueira, Pagode, Videogame, } \\
\text { Dança, Música, Passeios, Passeio de barco, Festa, Banho de piscina, Bola de } \\
\text { gude }\end{array}$
\end{tabular}

Figura 11 Agrupamento das palavras em conceitos-chave

Após o agrupamento, o quadro obtido foi o seguinte:

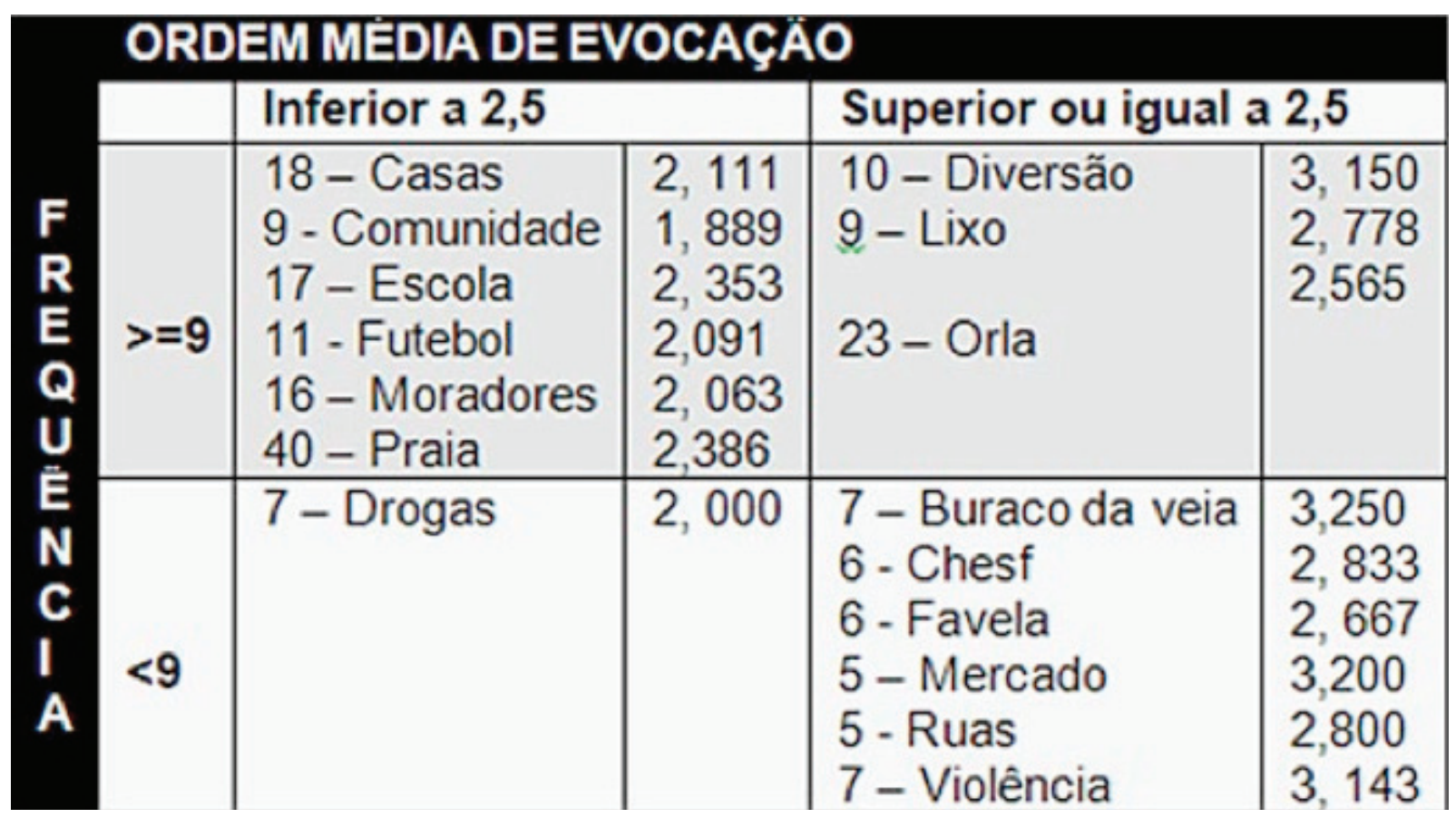

Figura 12 Resultado do exercício de representação social com 73 sujeitos

Nota: $\mathrm{N}^{\mathrm{o}}$ total de evocações $=358$; Total de palavras diferentes = 88. OME: Ordem Média de Evocação

A seguir, o estudo ganhou um cunho qualitativo, através do enfoque na busca da singularidade dos sentidos atribuídos pelos sujeitos. A análise sugere que a representação social do bairro gira em torno da ideia de moradia, significada tanto pela frequência quanto 
pela importância dada às palavras casas, moradores e comunidade, o que pode remeter à luta dos primeiros habitantes pela posse da terra. Compõem ainda o núcleo central praia, futebol e escolas.

No segundo quadrante, que aponta os elementos periféricos mais importantes, diversão, lixo e orla. No primeiro caso, está explícito o caráter lúdico da atividade. A palavra lixo surge como primeira evocação de sentido negativo, sinalizando para a falta de limpeza associada à paisagem do bairro. Já orla faz alusão à Avenida Brasília Formosa, fruto de um grande projeto de requalificação realizado no local.

No terceiro quadrante, que apresenta os elementos de contraste, percebe-se o problema das drogas. No último quadrante, mais referências à paisagem através da expressão Buraco da Véia, nome da praia "privativa" da comunidade, uma pequena faixa de areia frequentada pelos moradores. Compõem ainda o quadrante favela e violência. A inclusão da palavra Chesf referindo-se à Companhia Hidroelétrica do São Francisco foi explicada nos questionários e diz respeito ao projeto Verão Chesf, iniciativa realizada desde 2003 e que oferece atividades esportivas e shows.

A investigação revelou que as representações sociais deste grupo sobre Brasília Teimosa estão ancoradas em pelo menos quatro eixos: relações interpessoais (moradores, comunidade etc), locais e paisagens do bairro (naturais ou edificadas, como se percebe em praia e orla), evocações de cunho negativo (violência, drogas, lixo) e atividades do dia a dia (escola, futebol e diversão).

O resultado deste estudo inicial levou a mudanças no conteúdo informacional do artefato, procurando-se inserir ou substituir evocações presente no quadro de resultados no conteúdo das cartas do jogo, como forma de trazer o artefato para o universo semântico revelado no experimento. Abaixo, exemplo das alterações. Onde antes lia-se:

Você sabia que...

...As primeiras famílias começaram a ser retiradas das palafitas em 1982? Foi quando surgiu a comunidade da Vila da Prata. Em 1986, uma nova retirada deu origem à Vila Moacir Gomes e, em 1989, surgiu a Vila Teimosinho. Cada vez que um grupo de famílias era retirado das palafitas, outras pessoas que não tinham onde morar ocupavam a área novamente e construíam novas palafitas. Elas só deixaram de existir totalmente em 2004.

Passou-se a ler:

Você sabia que...

... As primeiras famílias começaram a ser retiradas das palafitas em 1982? Foi quando surgiu a comunidade da Vila da Prata. Em 1986, 
os moradores foram para as casas da Vila Moacir Gomes e, em 1989, surgiu a Vila Teimosinho. As palafitas só deixaram de existir em 2004

Após as alterações, o jogo foi novamente impresso para a realização do estudo final.

\section{Estudo final}

A realização do estudo final envolveu 25 sujeitos (17 meninos e 8 meninas, entre 11 e 14 anos). O grupo foi novamente formado por estudantes da escola Assis Chateaubriant e todos participaram de dois exercícios de representação social, um antes do contato com o jogo e outro após o uso da ferramenta. O estudo durou 16 dias, sendo três para realização de cinco partidas e dos exercícios de representação social antes do jogo e doze de intervalo até um último dia para as entrevistas finais.

Antes de cada partida, os sujeitos eram submetidos ao mesmo questionário com as cinco palavras associadas ao termo "Brasília Teimosa", seguida do rankeamento dos termos por importância. Após o questionário, iniciava-se a partida. Doze dias após as partidas, foi realizada a fase final do experimento, que consistia na repetição do exercício de representação social com o mesmo grupo de 25 sujeitos.

\subsection{Análise e discussão dos resultados}

A seguir, apresenta-se o resultado do exercício de representação social antes do jogo.

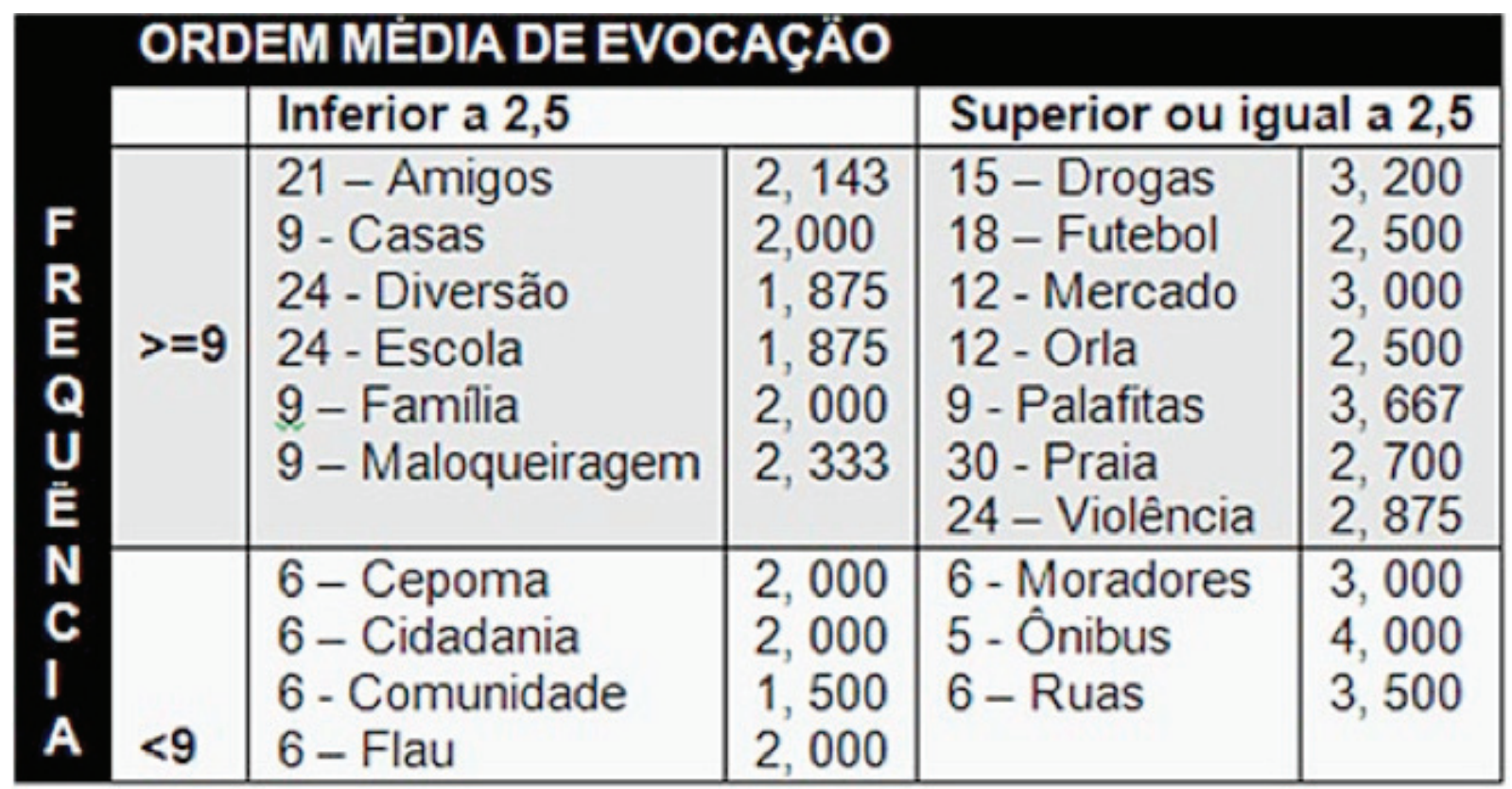

Figura 13 Resultado do exercício de representação social com 25 sujeitos (antes do jogo) 
Obteve-se o núcleo central da representação social com as palavras amigos e família, sinalizando a importância das relações interpessoais na estrutura da representação; casas, em referência aos locais e paisagens do bairro ou à forma de moradia para este grupo; diversão e escola como atividades do dia a dia. Por fim, aparece maloqueiragem que assume o caráter informal, trazendo para o núcleo central uma gíria comum ao grupo e um comportamento que assume conotação negativa.

No segundo quadrante encontram-se algumas palavras que integram as mesmas categorias da análise anterior, mas surgem novas evocações. Drogas e violência complementam a ideia de maloqueiragem no núcleo central; enquanto futebol e mercado podem ser inseridos no contexto das atividades do dia a dia. As demais evocações estão na categoria de paisagens/locais do bairro, mas encerram significados mais profundos. Praia e orla, por exemplo, dão conta da paisagem natural e da edificada no bairro após os vários projetos de requalificação ao qual Brasília Teimosa foi submetida até 2004, quando a Avenida Brasília Formosa foi entregue. Ao evocar essas palavras em separado parece clara a noção de que um trabalho de urbanização foi realizado, mudando a paisagem natural. Por fim, também na mesma categoria paisagens, aparece palafitas, com o detalhe que este tipo de construção não existe desde 2004, dando conta do quanto a história do bairro está presente no imaginário do grupo.

$\mathrm{Na}$ segunda periferia, o resultado se apresentou coeso em torno de uma ideia que não tinha surgido com tanta clareza no experimento anterior e que pode revelar um desejo latente deste grupo: a cidadania. A palavra aparece desmembrada em outras: Cepoma e Flau. Ambas são ONGs que atuam no bairro. O Centro de Educação Popular Mailde de Araújo (Cepoma) atende a 130 crianças com oficinas artísticas. Já a Turma do Flau atende 170 crianças com cursos de música, percussão, informática, capoeira e catequese. As duas estão contempladas nas cartas OBJETIVO e VOCÊ SABIA?. Por fim aparece comunidade, que pode ser entendida como a unidade formada por seus moradores através da organização social instituída desde a ocupação da área.

No último quadrante, estão moradores, numa referência à importância da organização social e das relações interpessoais, e ônibus e ruas, no que foi interpretado como evocações de mobilidade, critério de reconhecida importância para a mecânica do jogo, uma vez que os jogadores precisam se locomover pelas ruas do bairro para que cumpram seus objetivos.

\subsection{Representação social do bairro depois do jogo}

Doze dias após o término das partidas, foi realizado novo exercício com os 25 sujeitos, sendo aplicado o mesmo questionário. O objetivo era investigar se houve ou não mudanças no quadro de representações 
para o grupo e avaliar se as alterações poderiam estar relacionadas ao conteúdo trabalhado pelo artefato. A seguir, os resultados:

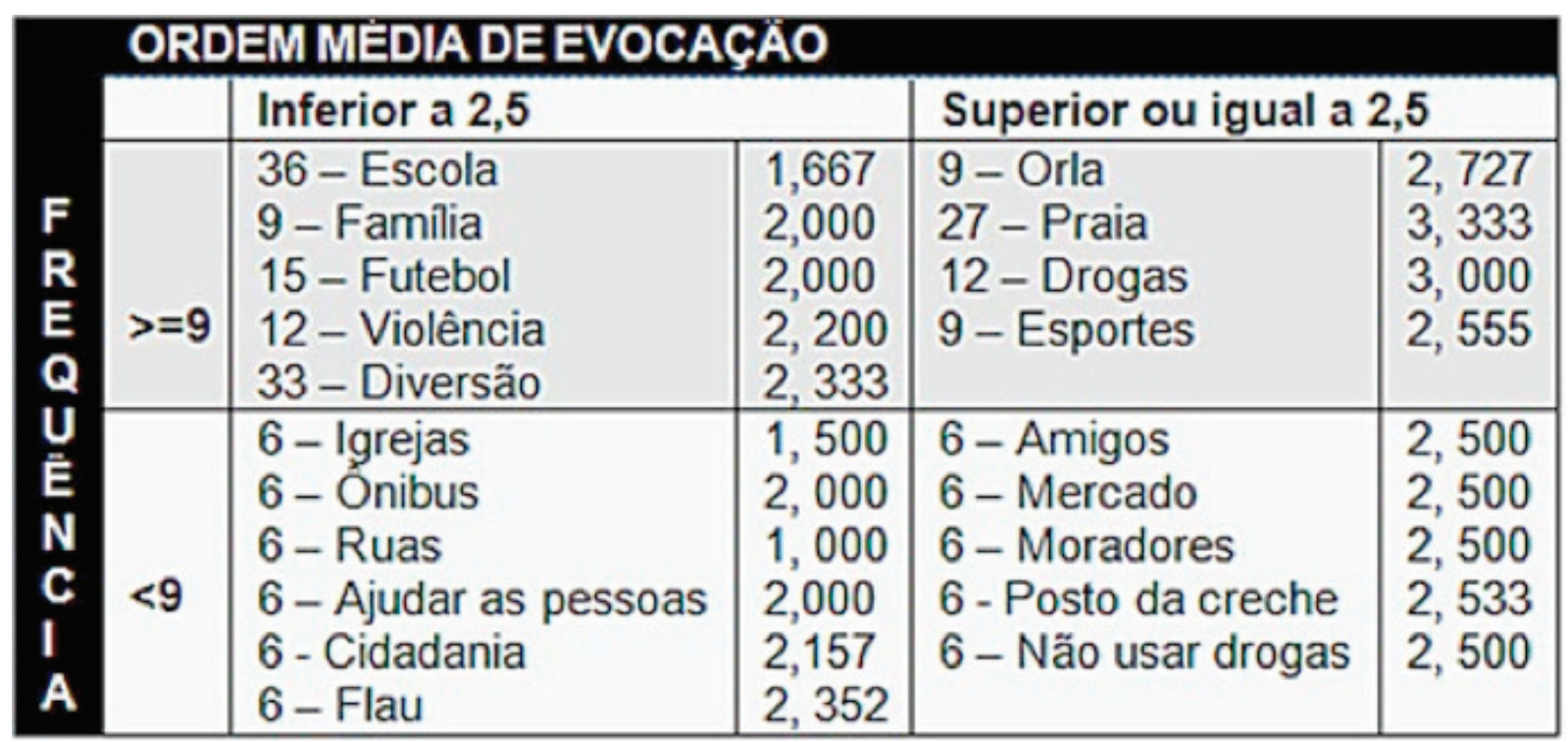

Figura 14 Resultado do exercício de representação social com 25 sujeitos (depois do jogo)

Das 20 palavras evocadas neste exercício, 15 já faziam parte do exercício anterior. Algumas ocupam as mesmas posições, principalmente no núcleo central, reforçando seu caráter inflexível e relativa independência do contexto imediato.

\begin{tabular}{|c|c|c|c|c|}
\hline \multirow[b]{2}{*}{$F$} & \multicolumn{2}{|c|}{$1^{\circ}$ QUADRANTE } & \multicolumn{2}{|c|}{$2^{\circ} \mathrm{QUADRANTE}$} \\
\hline & Antes do jogo & Depois do jogo & Antes do jogo & Depois do jogo \\
\hline $\begin{array}{l}\mathbf{R} \\
\mathbf{E} \\
\mathbf{Q} \\
\mathbf{U} \\
\mathbf{E} \\
\mathbf{N} \\
\mathbf{C}\end{array}$ & $\begin{array}{l}\text { 24-Escola } \\
\text { 24- Diversäo } \\
9 \text { - Familia } \\
21 \text { - Amigos } \\
\text { 9- Casas } \\
\text { 9-Maloqueiragem }\end{array}$ & $\begin{array}{l}36 \text { - Escola } \\
33 \text { - Diversäo } \\
9 \text { - Familia } \\
15 \text { - Futebol } \\
12 \text { - Violência }\end{array}$ & $\begin{array}{l}15 \text { - Drogas } \\
12 \text { - Orla } \\
30 \text { - Praia } \\
18 \text { - Futebol } \\
12 \text { - Mercado } \\
9 \text { - Palafitas } \\
24 \text { - Violência }\end{array}$ & $\begin{array}{l}12 \text { - Drogas } \\
9-\text { Orla } \\
27-\text { Praia } \\
9 \text { - Esportes }\end{array}$ \\
\hline $\begin{array}{l}\text { I } \\
\text { A }\end{array}$ & \multicolumn{2}{|c|}{$3^{\circ}$ QUADRANTE } & \multicolumn{2}{|c|}{$4^{\circ}$ QUADRANTE } \\
\hline & Antes do jogo & Depois do jogo & Antes do jogo & Depois do jogo \\
\hline & $\begin{array}{l}\text { 6- Cidadania } \\
6 \text { - Flau } \\
6 \text { - Comunidade } \\
\text { 6- Cepoma }\end{array}$ & $\begin{array}{l}6 \text { - Cidadania } \\
6 \text { - Flau } \\
6 \text { - Igreja } \\
6 \text { - Onibus } \\
6 \text { - Ruas } \\
6 \text { - Ajudar as } \\
\text { pessoas }\end{array}$ & $\begin{array}{l}6 \text { - Moradores } \\
5 \text { - Onibus } \\
6 \text { - Ruas }\end{array}$ & $\begin{array}{l}6 \text { - Moradores } \\
6 \text { - Amigos } \\
6 \text { - Mercado } \\
6 \text { - Posto da creche } \\
6 \text { - Não usar } \\
\text { drogas }\end{array}$ \\
\hline
\end{tabular}

Figura 15 Resultados antes e depois do jogo. As cores marcam as posições originais das palavras em seus quadrantes 
No primeiro quadrante, as palavras escola, diversão e família mantiveram suas posições. Futebol passou a fazer parte do núcleo, uma atividade de apelo entre a faixa etária dos sujeitos, encontrada no jogo pela inclusão da Escola de Futebol do Geraldo entre as cartas OBJETIVO e no conteúdo das cartas de AVANÇO. Também passou a compor o núcleo central o termo violência que antes ocupava o segundo quadrante. Como o jogo não faz referência à violência, é difícil imaginar que haja relação entre a ferramenta e a migração desta evocação da primeira periferia para o núcleo central. Aqui, é preciso fazer a observação que o exercício foi realizado na segunda-feira após um desfile cívico ocorrido na comunidade na sexta-feira anterior. $\mathrm{Na}$ ocasião, consumo de entorpecentes e agressões foram registrados. Ocorreu uma conversa sobre esta situação com todos os alunos da escola, podendo haver aqui influência do contexto neste resultado específico. Em relação ao experimento anterior, deixaram de fazer parte do núcleo central casas e maloqueiragem.

No segundo quadrante, mantiveram suas posições drogas, orla e praia. Houve a inclusão da evocação esportes. Registra-se ainda o desaparecimento da palavra palafitas, o que pode sinalizar o entendimento, a partir do contato com a história do bairro descrita no artefato, de que este tipo de construção não faz mais parte da paisagem do local.

No terceiro quadrante, permaneceram cidadania e flau e passaram a fazer parte igrejas e ajudar as pessoas. Sobre essas evocações, que não tinham aparecido no resultado anterior, é possível estabelecer uma relação direta com o jogo. As igrejas católica e evangélica do bairro estão presentes em quatro das quinze cartas OBJETIVO, tendo sido elas usadas em pelo menos duas das cinco partidas realizadas. A igreja católica também é conteúdo de uma das cartas VOCÊ SABIA? que conta a história do trabalho do padre Jaime Kohmichen na organização da comunidade durante a luta pela posse da terra. Já a ação de ajudar as pessoas é citada no conteúdo das cartas de AVANÇO.

Ainda neste quadrante, outra alteração que pode ter relação com o jogo é a presença de ruas e ônibus, que já constavam no resultado anterior mas ocupavam o quarto quadrante. A questão das ruas é muito presente no jogo. A mecânica do artefato foi desenvolvida para estimular a navegação pelo tabuleiro, de modo a apresentar a nomenclatura das ruas do bairro que, apesar de terem nomes de peixes há pelo menos uma década, continuam sendo chamadas pelas letras. A migração da palavra ônibus também pode ser entendida no mesmo contexto. Em relação à comparação entre o terceiro quadrante do resultado anterior e o atual, registra-se o desaparecimento da palavra Cepoma.

No quarto quadrante, apenas moradores se manteve. A periferia distante recebeu as palavras amigos e mercado, vindas do núcleo central e da segunda periferia, respectivamente. Não se encontra explicação coerente com o jogo para a palavra amigos ter sofrido este deslocamento. Ainda neste quadrante, duas outras evocações que não 
tinham sido mencionadas antes emergiram: posto da creche e não usar drogas. A primeira refere-se ao posto de saúde da comunidade, presente em pelo menos duas das quinze cartas OBJETIVO e também parte do conteúdo de educação ambiental citado em uma das cartas de AVANÇO. Já a expressão não usar drogas não aparenta ter relação com o jogo.

A análise dos resultados sugere que o contato - ainda que primeiro e único - com a ferramenta provocou algum impacto no quadro de representações sociais sobre Brasília Teimosa para este grupo. A inclusão de pelo menos três evocações novas e que possuem relação direta com o jogo (ajudar as pessoas, igreja e posto da creche), além de algumas migrações de palavras, apontam para o potencial da ferramenta no sentido de impactar pelo menos a forma como os sujeitos percebem o bairro.

\section{Considerações finais}

Os resultados obtidos com o estudo descrito apontam para a possibilidade de uso da Teoria das Representações Sociais no processo de configuração de artefatos de Design da Informação. O referencial teórico e a metodologia que embasaram este estudo parecem viabilizar uma forma de extrair tanto os campos semânticos comuns aos grupos sociais quanto as hierarquias e a estrutura organizacional do pensamento coletivo para um determinado grupo sobre um determinado tema.

À luz da Teoria do Núcleo Central, este tipo de análise da estrutura da representação social permite acessar a natureza do objeto e os tipos de relações que o grupo mantém com ele. No caso deste estudo, o objeto em questão era o bairro de Brasília Teimosa mas os procedimentos descritos neste artigo podem ser utilizados para fornecer informações relevantes em uma ou mais fases de investigação de problemas de Design, principalmente nos que estão inseridos no campo das relações entre indivíduos e sociedade.

A partir das diferenças entre os sistemas central e periférico, ainda é possível identificar as estruturas mais rígidas das representações sociais, bem como os espaços flexíveis e abertos a novas significações. De posse dessas informações, caberia ao designer, então, a partir das características e necessidades de cada projeto, tentar atuar dentro de um sistema que reforce representações consolidadas ou aproveite contradições e espaços "em aberto" para projetos inovadores ou portadores de novas práticas e intenções.

Embora considerado satisfatório para observar as mudanças no quadro de representações antes e depois do contato com o jogo que deu origem à pesquisa, acredita-se que houve uma pequena incorporação dos resultados obtidos durante os experimentos no conteúdo formal da ferramenta, ficando este campo em aberto para nova pesquisa - agora em nível de Doutorado - que está sendo 
realizada neste momento e pretende formalizar uma proposta de uso da metodologia originária da Teoria das Representações Sociais no campo do Design.

\section{Referências}

Bauman, z. (2005). Identidade. Tradução: Carlos Aberto Medeiros. Rio de Janeiro: Jorge Zahar Ed.

Bürdek, в. E. (2006). História, Teoria e Prática do Design de Produtos. Tradução:

Freddy Van Camp. São Paulo: Edgard Blücher.

DuvenN, G. (2008). Crianças enquanto atores sociais: as Representações Sociais em desenvolvimento. In: JOVCHELOVITCH, S;GUARESCHI, P. (Orgs.).

Textos em representações sociais. Petrópolis: Vozes.

Huizinga, J. (2000). Homo Ludens. São Paulo: Ed. Perspectiva SA.

JODELET, D. (2005). Loucuras e representações sociais. Tradução: Lucy Magalhães.

Petrópolis: Vozes.

moscovici, s. (2003). Representações sociais: investigações em psicologia social.

Tradução: Pedrinho Guareschi. Petrópolis: Vozes.

\section{Sobre os autores}

Maria Carolina Maia Monteiro,

<carolinamonteiro2001@gmail.com>

Jornalista formada pela UFPE em 1999. Mestre em Design pela UFPE (ano de conclusão - 2012). Atualmente é doutoranda do programa de Pós-Graduação em Design da UFPE.

Silvio Barreto Campello,

<sbcampello@gmail.com>

PhD, UFPE, Bolsista do CNPq - Brasil.

Artigo recebido em 03 dez. 2013,

aprovado em 12 dez. 2013. 